Фомченкова Лариса Владимировна

доктор экономических наук, доцент, профессор филиала Национального исследовательского университета «Московский энергетический институт» В г. Смоленске

\section{УПРАВЛЕНИЕ ПРОЦЕССОМ СТРАТЕГИЧЕСКОГО АНАЛИЗА И ПЛАНИРОВАНИЯ НА ОСНОВЕ ПРОЕКТНОГО ПОДХОДА [1]}

Аннотация:

Современные цифровые технологии, с одной стороны, предоставляют новые возможности для развития организации, а с другой - вступают в противоречие с традиционными методами и моделями стратегического менеджмента, которые не позволяют быстро принимать обоснованные решения. В связи с этим возникает актуальная научная задача формирования механизма cmpameгического анализа и планирования в условиях цифровой экономики. В статье обоснована целесообразность применения принципов и технологий управления проектами к процессу стратегического анализа и планирования развития предприятия. Предложена его модель на основе цикла ОODA и технологии Scrum, которая в отличие оm известных обеспечивает реализацию интегрированного подхода к аналитической деятельности и повышение эффективности взаимодействия аналитиков. Разработаны предложения по ее практическому внедрению в деятельность компании.

Ключевые слова:

стратегический анализ, стратегия, управление проектами, цикл ООDA, технология Scrum, принцип, планирование, развитие, организация, процесс.

\section{Fomchenkova Larisa Vladimirovna}

PhD in Economics, Associate Professor, Smolensk Branch of National Research University Moscow Power Engineering Institute

\section{STRATEGIC ANALYSIS AND PLANNING MANAGEMENT BASED ON PROJECT APPROACH [1]}

Summary:

On the one hand, modern digital technology provides new opportunities for the development of the organization. On the other hand, it is in conflict with traditional methods and models of strategic management that do not allow one to make prompt informed decisions. This raises the urgent scientific task of developing a mechanism of strategic analysis and planning process in the context of the digital economy. The study substantiates the feasibility of principles and technology of project management applied to strategic analysis and development planning of the organization. A model based on the OODA cycle and Scrum technology is proposed. Unlike well-known models, it allows one to implement an integrated approach to analytical activity and increase the efficiency of interaction among analysts. Recommendations for its practical implementation in the organization are developed.

Keywords: strategic analysis, strategy, project management, OODA cycle, Scrum technology, principle, planning, development, management, process.

В условиях трансформации экономики, когда данные в цифровой форме становятся основным ресурсом обеспечения конкурентоспособности организаций, возрастает важность информационных технологий и платформ для принятия управленческих решений. Среди фракторов, способствующих повышению эффективности менеджмента, особое значение приобретают цифровые бизнес-модели, позволяющие повысить организационную гибкость и клиентоориентированность. Зачастую они изменяются быстрее, чем разрабатывается новая продукция. При этом одними из ключевых условий развития предприятия являются наличие необходимой информации, а также умение руководителей и специалистов использовать цифровые технологии для стратегического анализа и обоснования стратегии.

Несмотря на многочисленные управленческие инновации, связанные с внедрением в стратегическую и оперативную аналитику сквозных цифрровых технологий [2], анализ и разработка стратегии базируются на функциональном и процессном подходах, актуальных для традиционной экономики. Идеи, высказанные в работах И. Ансофрфа, Дж. Арженти, К. Боумэна, Х. Виссемы, О.С. Виханского, Р. Гранта, И.Б. Гуркова, П. Друкера, Ф. Дэвида, Б. Карлоффра, П. Лоранжа, Б.З. Мильнера, М. Портера, А.Г. Поршнева, С.Р. Филоновича, А.Дж. Стрикленда, А.А. Томпсона, А. Чандлера и многих других отечественных и зарубежных ученых, позволили сформировать и реализовать на практике модели стратегического менеджмента, которые, по мнению Г. Минцберга [3], соответствуют предпринимательскому, адаптивному или плановому образу действий руководителей. Будучи эффективными в XX в., они оказываются непригодными для современных условий бизнеса, характеризующихся цифровой трансформацией. Это связано с высокой скоростью происходящих метаморфоз деловой среды и повышением сложности непрерывно изменяющихся задач, стоящих перед современными организациями, что не позволяет эффективно реализовывать традиционную модель стратегического менеджмента, состоящего из последовательных и регламентированных 
этапов. Вследствие этого собственники и работающие по контракту исполнительные директора многих российских компаний все чаще подменяют стратегические решения среднесрочными фринансовыми планами или конъюнктурными проектами, обеспечивающими сравнительно быстрые результаты. О неизбежности такой кризисной ситуации в стратегическом планировании Г. Минцберг предупреждал еще в 1990-е гг., призывая повысить гибкость и креативность стратегического процесса [4]. На основании изложенного возникает актуальная научная задача модификации модели стратегического анализа и планирования в условиях перехода к цифровой экономике.

Дефиницию понятия стратегии неоднократно пересматривали исследователи в ходе эволюции теории стратегического менеджмента [5], что меняло аналитические цели и задачи. В настоящее время данная категория рассматривается с позиции единства ее содержания, процесса и контекста, а также возможности формирования и развития в ходе реализации. Поскольку сегодня стратегия и план ее воплощения характеризуются целями, сроками, степенью сложности, однократностью, она может быть определена как долгосрочный проект со всеми присущими ему чертами (таблица 1).

Таблица 1 - Признаки стратегии как объекта управления проектами

\begin{tabular}{|c|c|c|}
\hline Признак & Проявление & Характеристика стратегии как проекта \\
\hline $\begin{array}{l}\text { Признак измене- } \\
\text { ний }\end{array}$ & $\begin{array}{l}\text { Целенаправленный перевод } \\
\text { проекта из текущего состояния в } \\
\text { желаемое }\end{array}$ & Развитие стратегии в процессе ее реализации \\
\hline $\begin{array}{ll}\text { Признак } & \text { конеч- } \\
\text { ной цели } & \end{array}$ & $\begin{array}{l}\text { Наличие комплекса целей про- } \\
\text { екта }\end{array}$ & $\begin{array}{l}\text { Ориентация стратегии на миссию и стратегиче- } \\
\text { ские цели организации }\end{array}$ \\
\hline $\begin{array}{l}\text { Признак ограни- } \\
\text { ченности требуе- } \\
\text { мых ресурсов }\end{array}$ & $\begin{array}{l}\text { Необходимость затрат времен- } \\
\text { ных, фринансовых, материаль- } \\
\text { ных, трудовых и информацион- } \\
\text { ных ресурсов для реализации } \\
\text { проекта, точное распределение } \\
\text { которых не всегда возможно }\end{array}$ & $\begin{array}{l}\text { В ходе стратегического анализа проводится } \\
\text { оценка ресурсов организации, требуемых для } \\
\text { обеспечения ее развития и конкурентоспособно- } \\
\text { сти в долгосрочной перспективе. Из-за неопреде- } \\
\text { ленности временные рамки могут пересматри- } \\
\text { ваться до тех пор, пока не будут достигнуты или } \\
\text { пересмотрены стратегические цели }\end{array}$ \\
\hline Признак новизны & однократен & шений, обеспе- \\
\hline $\begin{array}{l}\text { Признак систем- } \\
\text { ности }\end{array}$ & $\begin{array}{l}\text { Проект - это си } \\
\text { занных действІ }\end{array}$ & $\begin{array}{l}\text { ическая система содержания, } \\
\text {-a }\end{array}$ \\
\hline $\begin{array}{l}\text { Признак органи- } \\
\text { зационного обес- } \\
\text { печения }\end{array}$ & $\begin{array}{l}\text { Создание специфической орга- } \\
\text { низационной структуры на время } \\
\text { реализации проекта }\end{array}$ & $\begin{array}{l}\text { Распределение ответственности за разработку и } \\
\text { реализацию стратегии в рамках существующей } \\
\text { организационной структуры. Ее изменение в со- } \\
\text { ответствии с принятой к реализации стратегии }\end{array}$ \\
\hline
\end{tabular}

Данное обстоятельство позволяет применить к разработке и реализации стратегии принципы, методы и технологии управления проектами (таблица 2), что упорядочивает разработку стратегических решений, повышает эффективность их внедрения. Процесс стратегического анализа и планирования имеет возвратно-поступательное движение, что означает возможность корректировки результатов предыдущих этапов посредством обратной связи. Цикл OODA (Наблюдение - Ориентация - Решение - Действие), предложенный Дж. Бойдом для решения военных задач и получивший в настоящее время применение в управлении проектами [6], обеспечивает интеграцию и преемственность пробной, описательно-прогностической, предписывающей, операционной аналитики, а также дополняет методы и инструменты стратегического анализа и планирования цифровыми технологиями.

Таблица 2 - Реализация принципов управления проектами в процессе стратегического анализа и планирования развития организации

Методологические принципы проект- Реализация принципов при разработке и реализации ного управления 1

Принцип селективного управления (приоритетные проекты)

Принцип целевой ориентации (установление связей между потребностями в анализе и возможностями их удовлетворения)

Принцип полноты цикла управления проектами (реализация полного цикла управления) стратегии развития организации 2

Изменение приоритетов деятельности организации на основе результатов стратегического анализа

Постановка целей и задач анализа в зависимости от его вида (пробный, описательно-прогностический, предписывающий, операционный) в ходе разработки и реализации стратегии развития организации

Реализация цикла OODA при управлении процессом стратегического анализа и планирования 
Продолжение таблицы 2

\begin{tabular}{|l|l|}
\hline \multicolumn{1}{|c|}{1} & \multicolumn{1}{|c|}{2} \\
\hline $\begin{array}{l}\text { Принцип поэтапности управления проек- } \\
\text { тами }\end{array}$ & $\begin{array}{l}\text { Применение гибкой методологии Scrum для стратегического } \\
\text { анализа и планирования }\end{array}$ \\
\hline $\begin{array}{l}\text { Принцип иерархичности (выделение } \\
\text { иерархических уровней управления про- } \\
\text { ектами) }\end{array}$ & $\begin{array}{l}\text { Вовлечение специалистов в процесс интегрированной анали- } \\
\text { тики }\end{array}$ \\
\hline $\begin{array}{l}\text { Принцип многовариантности управлен- } \\
\text { ческих решений }\end{array}$ & $\begin{array}{l}\text { Выбор организационной модели стратегического анализа с } \\
\text { учетом состава исполнителей, стоимости и длительности вы- } \\
\text { полнения аналитических работ }\end{array}$ \\
\hline $\begin{array}{l}\text { Принцип системности (разработка мер } \\
\text { по реализации проекта во взаимосвязи с } \\
\text { концепцией организационного развития) }\end{array}$ & $\begin{array}{l}\text { Разработка организационно-экономического, технологиче- } \\
\text { ческого анализа и планирования во взаимосвязи с концепцией } \\
\text { развития предприятия }\end{array}$ \\
\hline $\begin{array}{l}\text { Принцип комплексности (разработка } \\
\text { элементов проекта в соответствии с его } \\
\text { главной целью) }\end{array}$ & $\begin{array}{l}\text { Выбор направлений, моделей и инструментов стратегиче- } \\
\text { ско анализа в зависимости от целей и задач аналитической } \\
\text { деятельности }\end{array}$ \\
\hline $\begin{array}{l}\text { Принцип сбалансированности (обеспе- } \\
\text { чение проекта ресурсами) }\end{array}$ & $\begin{array}{l}\text { Обеспечение реализации стратегии фринансовыми, информа- } \\
\text { ционными, материальными, трудовыми ресурсами }\end{array}$ \\
\hline
\end{tabular}

В ходе первого цикла пробной аналитики (стадия «Наблюдение») для сбора и обработки большого количества данных в целях поиска и уточнения первоначальных идей, подбора источников информации наряду с известными приемами научного исследования может быть успешно применена технология анализа больших данных (Big Data), позволяющая значительно сокращать время и трудоемкость аналитических операций. В соответствии с принципами дизайн-мышления, хорошо зарекомендовавшего себя в ходе разработки бизнес-моделей [7], этот этап циклически повторяется до тех пор, пока не будет сформирована методологическая и информационная основа для осуществления описательно-прогностического анализа.

Основной целью описательной аналитики является оценка достигнутых результатов и эффективности реализуемой стратегии, прогностический стратегический анализ нацелен на предсказание изменения деловой среды. Они соответствуют этапу «Ориентация», в ходе которого с помощью известных методов, технологий и инструментов формируются стратегические альтернативы развития организации. Реализация принципа комплексности в данном цикле процесса стратегического анализа и планирования предполагает выбор методологии, технических приемов и средств аналитической деятельности в зависимости от стадии жизненного цикла объекта исследования и доступности информации о нем.

На этапе «Решение» проводится предписывающий анализ, направленный на формирование информационной базы для выбора стратегии и планирования действий по ее осуществлению. Последующие циклы связаны с операционной аналитикой, которая в краткосрочном периоде обеспечивает обоснованность действий организации в изменяющихся условиях бизнеса. С помощью цифровых технологий и платформ она встраивается в бизнес-процессы, генерирует решения и реализует их без вмешательства человека.

Рассматриваемая модель обеспечивает переход к сквозному стратегическому анализу, который интегрирует описание прошлых тенденций, прогнозы и предписывающие действия, связанные не только с формированием стратегических решений, но и с их корректировкой в ходе реализации. В результате преодолевается линейный и каскадный характер действий, когда все этапы планируются заранее, а изменения возможны с помощью обратной связи только после получения информации об отклонении результатов деятельности от стратегических целей, что неизбежно приводит к запаздыванию решений. Модель стратегического анализа и планирования на основе цикла OODA позволяет формировать и модифицировать стратегию в ходе ее воплощения, а при внедрении цифровых моделей бизнеса - использовать аналитические продукты для совершенствования предлагаемых товаров и услуг и трансформации среды бизнеса.

Реализация описанного процесса тесным образом связана с изменением организации аналитической работы. Традиционная модель стратегического управления зачастую предполагает привлечение преимущественно внешних консультантов для сбора данных и подготовки информационной базы для принятия стратегических решений. В отдельных ситуациях на временной основе могут привлекаться специалисты организации. Централизованное управление аналитической деятельностью позволяет осуществлять стратегический анализ, результаты которого представляют ценность на корпоративном уровне и недостаточны для отдельных направлений бизнеса. В рамках развитых корпоративных моделей структура становится все более децентрализованной, аналитическая деятельность переносится в бизнес-подразделения и координируется высшим менеджментом. В ряде случаев, когда требуется комплексный анализ проблемы, 
целесообразным становится фрормирование межфункциональных команд. Однако по сравнению с аналитическим отделом такая модель является более сложной для применения на практике.

Внедрение предлагаемого циклического процесса интегрированного стратегического анализа и планирования предусматривает использование гибкой технологии управления проектами Scrum (англ. scrum - схватка) [8], которая обеспечивает эффрективное взаимодействие специалистов для достижения цели (рисунок 1). В этом случае деятельность аналитической команды (отдела) можно представить в виде цикла, включающего следующие этапы:

- определение целей и задач аналитической деятельности;

- подбор членов аналитической команды (исполнителей) из числа специалистов организации и внешних консультантов;

- выбор (назначение) лидера (Scrum-мастера), который контролирует процесс интегрированного стратегического анализа;

- составление списка требований к результатам работы команды (отдела); (спринт);

- проведение первичного собрания, на котором определяются сроки выполнения заданий

- создание Scrum-доски со списком выполняемых работ в трех статусах - «нужно сделать», «в работе», «сделано»;

- ежедневное проведение Scrum-собраний, где уточняются ближайшие задачи и распределяются задания;

- итоговая встреча, на которой анализируется деятельность команды.

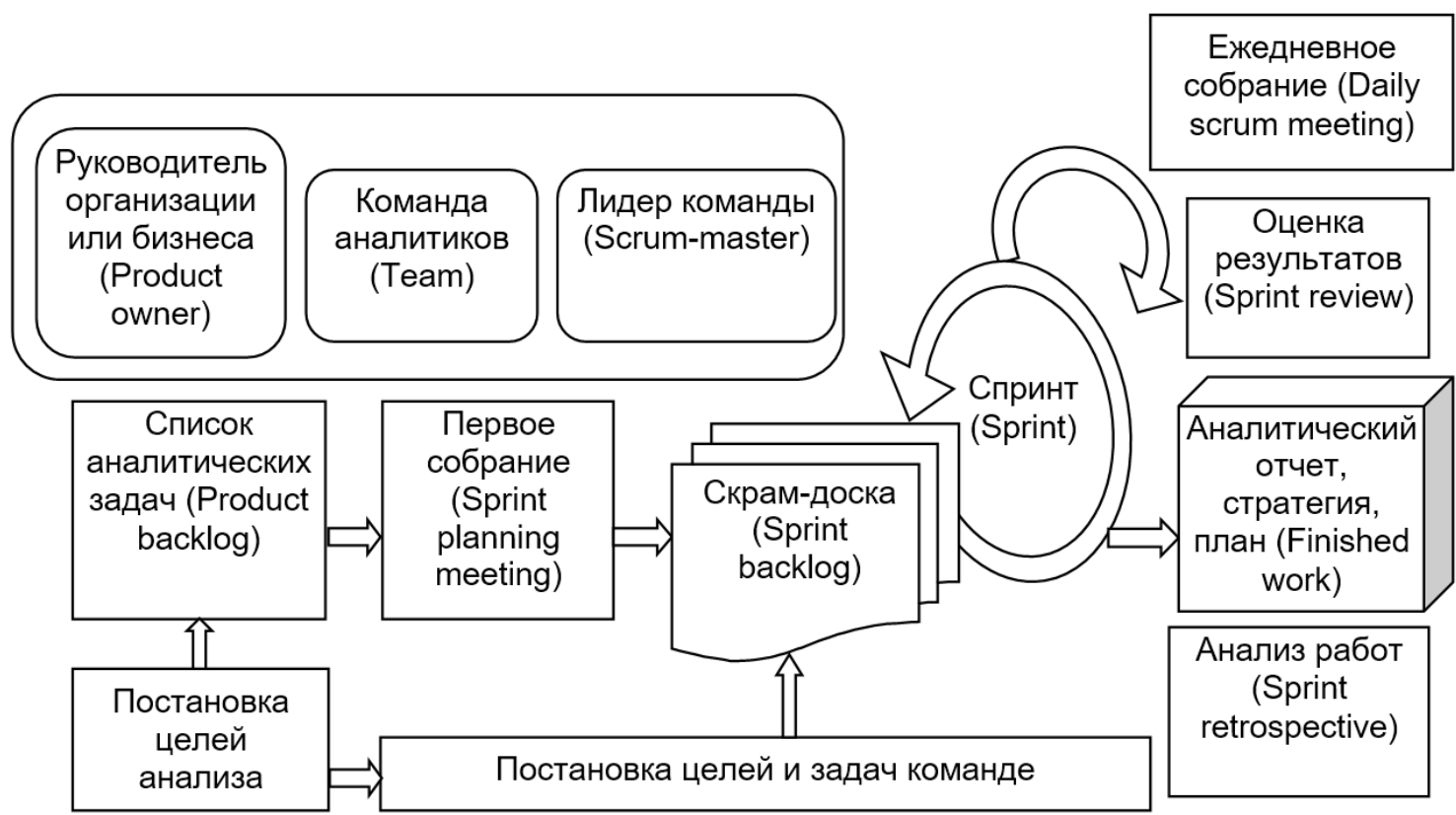

Рисунок 1 - Организация процесса стратегического анализа и планирования
на основе технологии Scrum

При этом обеспечивается тесное взаимодействие руководителей и аналитиков организации с внешними консультантами, достигаются ориентация на результат и оперативная реакция на изменения. Подобный процесс способствует накоплению опыта аналитической деятельности и повышению ее качества, уровень которого оценивается степенью удовлетворенности пользователей аналитической информации при принятии стратегических решений.

Современная аналитика представляет собой интегрированный автоматизированный процесс принятия решений, который предписывает осуществление определенных действий в режиме реального времени. Традиционный стратегический анализ, дополненный предписывающей аналитикой, является не просто функцией менеджмента, в условиях цифровой экономики он превращается в ключевой элемент, способный преобразовать выпускаемый продукт и изменить отрасль бизнеса. Технология управления проектами Scrum позволяет в полной мере реализовать концепцию интегрированного стратегического анализа. Гибкий подход к организации деятельности аналитической группы обеспечивает тесное взаимодействие сотрудников, повышает их мотивацию, что в конечном счете не только способствует формированию обоснованных стратегических решений, но и гарантирует совершенствование бизнес-модели в условиях цифровой экономики. 


\section{Ссылки и примечания:}

1. Работа выполнена при финансовой поддержке РФФИ и администрации Смоленской области (проект № 18-410670005).

2. Фрэнкс Б. Революция в аналитике: Как в эпоху Big Data улучшить ваш бизнес с помощью операционной аналитики. M., 2018.

3. Минцберг Г., Альстранд Б., Лампель Дж. Стратегическое сафари. Экскурсия по дебрям стратегического менеджмента. М., 2013.

4. Mintzberg H. The Rise and Fall of Strategic Planning. N. Y., 1994

5. Катькало В.С. Эволюция теории стратегического управления. 2-е изд. СПб., 2008

6. Сазерленд Дж. Scrum. Революционный метод управления проектами. М., 2017.

7. Гассман О., Франкенбергер К., Шик М. Бизнес-модели: 55 лучших шаблонов. М., 2016.

8. Стеллман Э., Грин Дж. Постигая Agile. Ценности, принципы, методологии. М., 2017

\section{References:}

Franks, B 2018, Revolution in Analytics: How to Improve your Business in the Era of Big Data with the Help of Operational Analytics, Moscow, (in Russian).

Gassman, O, Frankenberger, K \& Schick, M 2016, Business Models: 55 Best Templates, Moscow, (in Russian).

Katkalo, VS 2008, The Evolution of the Theory of Strategic Management, $2^{\text {nd }}$ ed., St. Petersburg, (in Russian).

Mintzberg, H 1994, The Rise and Fall of Strategic Planning, New York.

Mintzberg, H, Alstrend, B \& Lampel, J 2012, Strategic Safari. Excursion in the Wilds of Strategic Management, Moscow, (in Russian).

Stellman, E \& Green, J 2017, Comprehending Agile. Values, principles, methodologies, Moscow, (in Russian).

Sutherland, J 2017, Scrum. A Revolutionary Project Management Method, Moscow, (in Russian). 